\title{
EL PALÍNDROMO DE ANTÍGONA, O EL EMPODERAMIENTO PACIFISTA A TRAVÉS DEL ARTE ${ }^{1}$
}

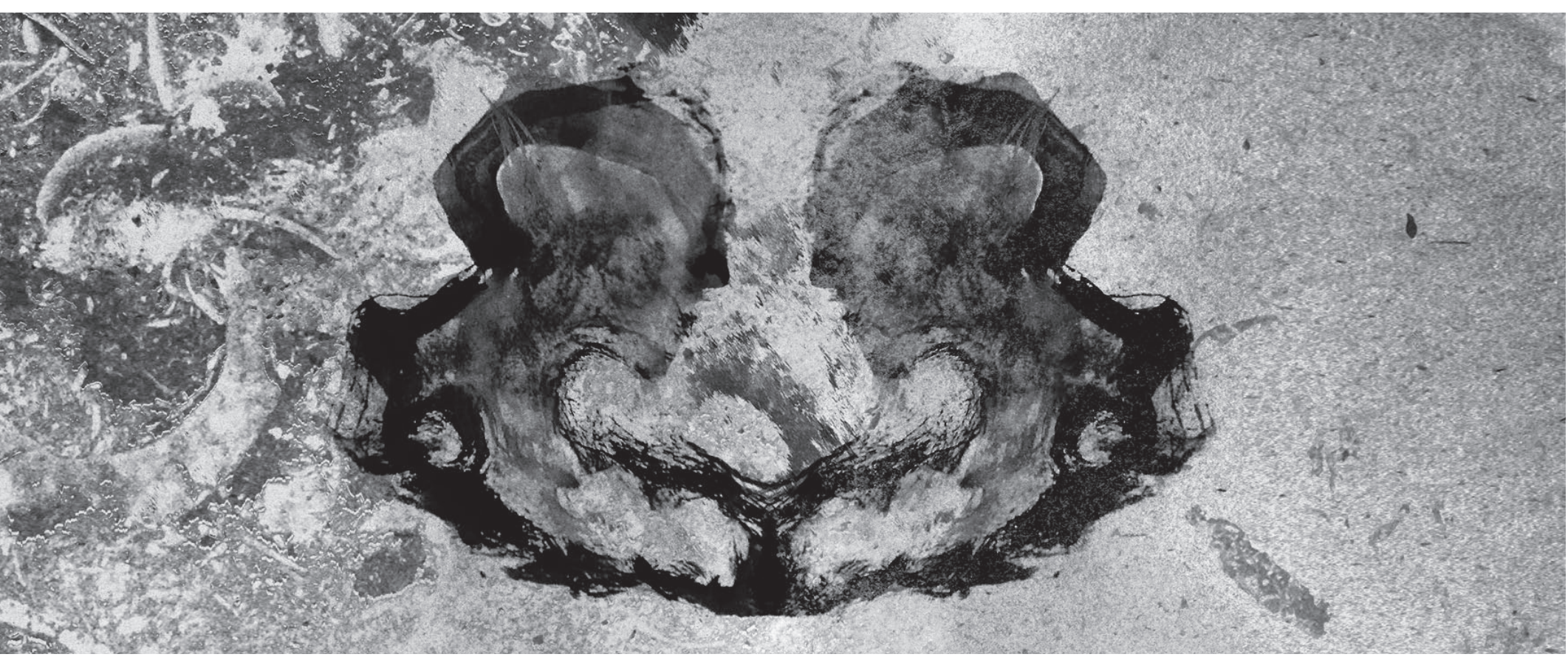

\section{THE PALINDROME OF ANTIGONE, OR THE PACIFIST EMPOWERMENT THROUGH ART}

Por:

Alejandra Toro Calonje

Profesora Escuela de Comunicación Social

Universidad del Valle

atocade@gmail.com

Resumen: "Ten la opinión que te parezca, que yo lo enterraré. Hermoso me es morir haciéndolo" (Sófocles, 2009, p. 35). Livianas y desprendidas, las palabras de Antígona son el reflejo de su alma. Llora la muerte de su hermano Polinices, a quien su tío, el rey Creonte ha decidido dejar insepulto por traición. Pero con convicción, Antígona emprende sola la colosal tarea de enterrar a su hermano, a pesar de ser condenada a muerte por tal desobediencia. Antígona deja su condición de víctima en el momento en que cubre de un fino polvo de tierra el cuerpo de Polinices. Su fragilidad se ha hecho visible, su resistencia se tornó resiliencia, quedando intacta su capacidad de acción.

Una maravillosa metáfora ilustra el desafío de Antígona: es el palíndromo "reconocer", una palabra que se lee igual en ambos sentidos, como si un espejo la conjugara. Este es el palíndromo de Antígona.

Palabras Clave: Fragilidad, Poder, Resiliencia, Empoderamiento, Arte, Visibilidad, Otredad, Cuerpo, Espectador. 
Abstract: "You have made your choice, you can be what you want to be. But I will bury him; and if I must die, I say that this crime is holy: I shall lie down with him in death", (Sophocles, 2009: 35). Lightweight and detached, the words of Antigone are the reflection of his soul, she cries the dead of his brother Polynices, whose uncle, the king Creon, has decided leave unburied by treason. But with conviction, Antigone engages in the colossal task to bury his brother, despite of be condemned to dead for such disobedience, Antigone leaves his victim condition in the moment that she covers of a thin dust of earth the body of Polynices. His fragility has become visible, his resistance has become on resilience, leaving intact his action capacity.

A wonderful metaphor illustrates the challenge of Antigone: the palindrome "reconocer" an Spanish word that reads the same both ways, as if a mirror would combine. This is the palindrome of Antigone.

Keywords: Fragility, Power, Empowerment, Art, Visibility, Otherness, Body, Spectator.

Para Francisco "Paco" Muñoz, el artífice de esta paz imperfecta, mi maestro y mi amigo. Descansa en paz.

Sólo cuando empezó a desmontar la puerta del cuartito, Úrsula se atrevió a preguntarle por qué lo hacía, y él contestó con una cierta amargura:"Puesto que nadie quiere irse, nos iremos solos." Úrsula no se alteró.

- No nos iremos - dijo-Aquí nos quedamos, porque aquí tenemos un hijo.

- Todavía no tenemos un muerto - dijo él-. Uno no es de ninguna parte mientras no tenga un muerto bajo la tierra.

Gabriel García Márquez. Cien años de soledad.

Vienen con sus foticos arrugadas. Unas cédulas percudidas con un retrato que ni se reconoce. Unas fotos viejas (o a veces no tanto), llenas de sudor y dolor. Lo único que les queda de sus seres queridos. Unas imágenes metidas en bolsas plásticas, en carpetas transparentes, tristes de tanto manoseo. Son rostros indígenas, negros, mulatos, zambos, pobres, campesinos, jóvenes, mujeres, viejos y niños. Muchas mujeres. El rostro cerrado, adusto. Se reconocen en el sufrimiento del otro. "¿A usted también se le llevaron a alguien?” me pregunta una señora en la población de Trujillo, con la cara curtida por el sol, el tiempo y las lágrimas. En tamaño oficio, la imagen de su hijo muerto. Desaparecido, dice ella. 
"Él se levantaba, él hacia su desayuno, le gustaba hacer chocolate, le gustaba vestir bonito, con ropa deportiva. Era muy aseado, le gustaba mucho trabajar. Yo no sé por qué me lo acusaron de todo eso... hasta que me lo desaparecieron.” Me lo desaparecieron. Interpela la conjugación del verbo. Esta es otra madre, que da testimonio de su pena en el documental de Nicolás Rincón Los abrazos del río (2010). Ella tampoco ha encontrado el cuerpo de su hijo.

“QQué pasó con mi esposo? ¿Y con mi cuñada? ¡Qué hicieron con ellos! ¡Que me entreguen el cuerpo, que me digan donde están!”, exige una señora en julio 2005, en la audiencia de careo de paramilitares y víctimas en el marco de la Ley de Justicia y Paz que ilustra el documental Impunity de Juan José Lozano y Hollmann Morris (2011). Los sobrevivientes, chanclas y abanicos de papel, escuchan los horrores sin inmutarse. Cuchichean tímidamente. Como si la incomprensión fuera demasiado fuerte. No hay rebelión ya. El miedo lo puede todo.

La historia contemporánea de Colombia está plagada de relatos de horror y muerte. Las historias de los muertos cohabitan a diario con los vivos. Muertes violentas, violaciones, masacres, desplazamientos forzados, reclutamientos ilícitos, esclavitud sexual, terrorismo, secuestros, desapariciones forzadas..., tal es el léxico que ha impuesto el conflicto armado que desangra mi país desde hace varias décadas. Las urgencias permanecen en Colombia, las preguntas son lancinantes: ¿cuántos son los muertos de esta guerra?, ¿cuántos los desaparecidos?, ¿dónde están?

Pues acá, en esta tierra de selva frondosa y mariposas amarillas, no hay cuerpos. O quizás sí, hay demasiados. Pero no enteros. Lo que nos ha dejado esta sangrienta guerra civil que azota a Colombia desde hace 60 años son pedazos de cuerpos. Miembros, torsos, costales rebosando cabezas, fragmentos de tibia o de pelvis, cadáveres mutilados... eso es lo que han escupido las fosas comunes o lo que el río ha abandonado en alguna ribera antioqueña, antes de su inexorable descomposición. Cuerpos desaparecidos. La ausencia de cuerpo como significante del terror. El cuerpo como objeto "des-corporizado". Ausentes pero por siempre presentes en la memoria de los sobrevivientes, de sus familiares. La presencia de la ausencia.

Unas botas en una fosa común, la marquilla de una camiseta, una marca en el antebrazo. Una desaparición forzada es una muerte sin cadáver y sin duelo. Los sobrevivientes quedan inmóviles con el retrato congelado de sus desaparecidos. En silencio y estáticos. 


\section{Antígona, fragilidad y fuerza}

"Quebradizo, y que con facilidad se hace pedazos", dice la Real Academia de la lengua. "La fragilidad es la cualidad de los objetos y materiales de perder su estado original con facilidad. Aunque técnicamente la fragilidad se define más propiamente como la capacidad de un material de fracturarse con escasa deformación". Escasa deformación... Ya en esta definición técnica encontrada en el Diccionario sobre fragilidad se integra cierta noción de resistencia.

Así es la Antígona de Sófocles. Frágil y sin embargo, tan resuelta... Las mujeres, esclavas o libres, no son consideradas ciudadanas en el Estado griego. Se sitúan, por definición, por debajo del Estado. Por lo general, en las tragedias griegas, es el héroe -o la fuerza que lo impulsa- quien toma las resoluciones irrevocables que subyacen toda tragedia. Pero Antígona sobrepasa los límites impuestos por el sexo; esta enclenque muchachita, casi una niña en la versión de Anouilh, hace lo que ningún hombre se atreve, lo que su hermana Ismena no concibe por su condición de mujer. Antígona sabe que debe darle sepultura a su hermano. "Tú estás con vida; la mía, sin embargo, ha terminado hace tiempo, para poder ayudar a los muertos" (Sófocles, 2009, p. 63). Con inexorable serenidad, esta figura frágil, como una brizna de aire, se enfrenta a todo el aparato ideológico y del arsenal del Estado por una decisión ética individual e irreductible, la de no dejar insepulto a su hermano. Sin cuestionarse, casi que naturalmente, enfrenta el poder del Rey. Su determinación se ve reflejada en las siguientes frases: "(Creonte) no tiene atribución alguna para impedirme mis deberes"; "Pues bien, cuando se me agoten las fuerzas, desistiré", o más allá: "No hay deshonra alguna en practicar la piedad con los nacidos de la mismas entrañas" (Sófocles, 2009, pp. 34,37 y 58$)$. 
Es no obstante en la versión de Antígona de Jean Anouilh (2009) donde se percibe más claramente esa especie de ineluctabilidad que la embarga:

- Ismena: No podemos.

- Antígona (después de un silencio, con su vocecita): ¿Por qué?

- Nos condenaría a muerte.

- Por supuesto. Cada uno su papel. Él debe condenarnos a muerte, y nosotras debemos enterrar a nuestro hermano. Ésos son los papeles. ¿Qué quieres que hagamos?

- Yo no quiero morir.

- Antígona (dulcemente):Yo tampoco hubiera querido morir. (p. 135)

Antígona, a diferencia de su padre Edipo, sabe cuál es su destino y no trata de enmendarlo. Lo afronta con el convencimiento de ser quien lo construye, de decidir, de tomar parte activa en lo que será el final de su vida. Como dice Luis Gil:

Antígona defiende hasta el sacrificio de la vida una norma de derecho divino - la de recibir sepultura - que es a la vez un derecho humano. (...) Incluso una muchacha débil y abandonada por todos -y he aquí el hondo sentido de la elección del personaje femenino-puede encontrar en su persona las energías suficientes para sacrificarse por los eternos principios que rigen la vida de los hombres, con la consoladora seguridad -en esto reside el mensaje sofocleo a sus compatriotas y a todos los hombres - de que su sacrificio no será estéril (Sófocles, 2009, pp. 20 y 25).

Este acto la distingue de las demás víctimas. Antígona se ha empoderado. Desobedece la ley del Estado pues sabe que la razón está de su lado. Se erige pacíficamente contra la injusticia del gobernante en nombre de todos los desprotegidos de la ciudad.

150 Creemos que la fuerza de Antígona radica precisamente en su vulnerabilidad. Trataremos de exponer en este artículo que es en su fragilidad donde la heroína de la tragedia encuentra la fuerza para revertir el mundo.

\section{Empoderamiento pacifista desde la Investigación para la Paz}

Es en los planteamientos de los investigadores del Instituto de la Paz y los Conflictos de la Universidad de Granada que encontramos los argumentos más importantes para dar soporte a lo aquí avanzado. La finalidad primera de este Instituto es divulgar una cultura de paz, entendiendo por este concepto algo mucho más amplio que la ausencia de guerra.

El término de Paz imperfecta fue introducido por el Profesor Francisco Muñoz, padre fundador de este concepto, hace 16 años, como una construcción hermenéutica que surge de la teoría sobre la Investigación para la paz, articulando conceptos, métodos y enfoques que nos dotan actualmente de mejores herramientas para analizar y comprender 
los diversos fenómenos relacionados con la Paz y los Derechos Humanos. Así definen los investigadores españoles este término:

Hacemos uso del concepto de paz imperfecta para definir aquellos espacios e instancias en las que se pueden detectar acciones que crean paz, a pesar de que estén en contextos en los que existen los conflictos y la violencia. De esta manera entendemos la paz imperfecta como una categoría de análisis que reconoce los conflictos en los que las personas y/o grupos humanos han optado por facilitar la satisfacción las necesidades de los otros, sin que ninguna causa ajena a sus voluntades lo haya impedido (Muñoz; Herrera; Molina \& Sánchez, 2005, p. 29).

Así, uno de los aspectos fundamentales de los Estudios para la Paz es el análisis de los conflictos. Los conflictos como una "circunstancia inherente al ser humano, con la que se abren enormes capacidades creativas, generadoras de bienestar, sin que ello suponga negar sus derivaciones violentas" (Muñoz \& Molina, s.f.).

Decía Francisco Muñoz (2001):

El conflicto forma parte del universo, de todas las realidades que lo componen y de las relaciones que se establecen entre ellas (...). Casi nos atreveríamos a decir que el «conflicto» es una característica de los seres vivos que en su intento de perpetuarse como individuos frente a la muerte y como especie frente a la extinción pretenden utilizar en su beneficio los recursos y la energía disponible en su entorno.

De esta manera, todas las actividades humanas están insertas en la complejidad; ésta es resultante de los procesos expansivos y evolutivos del Universo y de la Tierra. Los seres vivos han encontrado soluciones adaptativas donde se desarrollan para acceder a la energía, mantener el equilibrio físico y químico, conservar sus formas de organización, frenar la agresión externa, garantizar su desarrollo y reproducción, obteniendo así un equilibrio dinámico entre su propia evolución y la del ambiente donde se desarrollan. Los procesos de adaptación de los homínidos pasaban por la socialización y el reconocimiento del otro, traduciéndose en cooperación y armonía. De esta manera, la Paz se ha constituido como la respuesta de los seres humanos a los desafíos del medio ambiente, a la búsqueda de mayor equilibrio y armonía con su medio, a un mayor grado de organización dentro de la especie humana. La Paz es pues buscar el más alto grado de bienestar para su comunidad. Es responder sin violencia al impacto del conflicto armado.

El conflicto y la cooperación son las dos caras de la misma moneda de las relaciones humanas. La cooperación, entendida como "una acción de dos o más agentes que obran juntos y producen un mismo objetivo, o como ayuda, auxilio o socorro que se presta para el logro de alguna cosa" (Muñoz \& Molina, s.f.). Es un compromiso altruista y filantrópico. 
Según esta perspectiva, el empoderamiento pacifista hace parte de esas interacciones que puede generar un sistema basado en la complejidad. Esta praxis, que implica una estrategia de acción consciente, es definida de la siguiente manera: "un reconocimiento de las realidades, prácticas y acciones pacifistas y sus capacidades para actuar y transformar su entorno más o menos cercano; y para impulsar y promover la creación de redes entre todos los actores que de una u otra forma tienen intereses en promocionar la paz" (Muñoz; Herrera; Molina \& Sánchez, 2005, p. 138).

Como una reacción ante el poder, el empoderamiento pacifista busca restituir en las personas de lo más característicamente humano: la satisfacción directa de sus necesidades. La Investigación para la paz se inspira de la propuesta de Manfred Max Neef, que, desde la perspectiva de un desarrollo a escala humana, establece una taxonomía comprensible de las necesidades humanas: subsistencia, protección, afecto, entendimiento, participación, ocio, creación, identidad y libertad. Unas variables esenciales pues es hacia la satisfacción de estas carencias en la humanidad que tiende la Paz imperfecta.

¿Qué poder tiene la Paz para influir en los aspectos personales políticos, sociales, qué fuerza tiene para influenciar las agendas?, se preguntaba Francisco Muñoz en la conferencia El campo transdisciplinar para la Paz. La respuesta radica en el empoderamiento pacifista. El empoderamiento pacifista, insistía Francisco Muñoz, no está condicionado por la violencia. Rompe con la perspectiva bipolar del enemigo. Al reconocer su capacidades, se habla más bien en términos de "adversario", se le reconoce su dignidad, se acepta que él también es capaz de hacer paz y que es necesario para nosotros. Reconocer al otro es tomar conciencia plena de su existencia. Eso es lo que nos permite hacer la paz con ellos. La paz imperfecta nos da la posibilidad de construir y reconocer pequeños momentos de paz que nos permiten seguir avanzando. Es un flujo dinámico y envolvente: la paz imperfecta alimenta el empoderamiento pacifista, mientras éste fortalece el tejido social y las posibilidades de generar paz.

Francisco Muñoz afirmaba que los desafíos para la paz están pues en deconstruir la violencia, quitándole el protagonismo, incluir la paz en las agendas estatales, renovar los presupuestos epistemológicos y ontológicos, investigar la paz como campo transdisciplinar, y por último, argumento esencial para este artículo, reconocer la fragilidad como un elemento presente y de gran importancia para la complejidad.

Pensar la paz imperfecta es "reorganizar nuestras neuronas". Es reinvertir nuestro pensamiento. Es fundamental ser capaces de deconstruir para volver a construir, desaprender de aquello que nos impulsa a la violencia, fomentando la convivencia pacífica y lograr transformar la sociedad. "Tenemos un potencial enorme para la construcción de la paz", insistía Francisco.

Nos gustaría huir, en la medida de lo posible, del sentido negativo que el término imperfecto arrastra. No se trata de negar una forma de «hacer», de no-hacer. Sino más bien una demanda de actuar, crear, engendrar, incidir, llevar a cabo, obrar, operar, practicar, proceder, realizar en un sentido de transformación positiva, propositiva de cambio hacia, de regulación de los conflictos. (Muñoz, 2001) 
Por otro lado, Vicent Martínez, Doctor en Filosofía y director honorífico de la Cátedra Unesco de Filosofía para la Paz, describe en su artículo Saber hacer las paces (2000) los principales ejes sobre los cuales articular el giro epistemológico que debemos emprender al construir nuestras hipótesis en el marco de la Investigación para la paz. En esta forma nueva de generar conocimiento, lo esencial es el otro. En la otredad es que el planteamiento de la Investigación para la paz toma toda su fuerza: aquello que se decía objetivo, pasa a ser intersubjetivo; el observador distante que adquiere conocimiento pasa a ser partícipe de los procesos de reconstrucción de escenarios de paz. El conocimiento deja de ser una relación entre sujeto y objeto para convertirse en una relación entre sujetos y personas que reclaman el derecho a la interlocución. Estamos hablando de una epistemología comprometida con los valores y la justicia, aquella que se calificaba de neutra, que se vuelve solidaria, en un lugar donde el contrato social inicial que estipulaba la igualdad de todos marca ahora explícitamente las diferencias: cada uno reclama ser reconocido en su individualidad y particularidad. No se habla ya de una razón en singular sino que se comprometen las razones, en plural. Se permiten tener en cuenta los sentimientos, las emociones, el cariño, la ternura. El mundo deja de ser abstracto para convertirse en diversidad de lugares locales, los seres humanos volvemos a ser parte de la naturaleza y ésta deja de ser un objeto que debemos controlar. Reivindicamos nuestro compromiso con la defensa del medio ambiente y nuestro lugar en la Tierra. Se crea la categoría de análisis de género, que permite la reedificación de un nuevo lugar de la mujer y de nuevas formas de conjugar tanto lo femenino como lo masculino. Se pasa del paradigma de la conciencia al de la con-ciencia, al de la Comunicación, a aquel saber que se crea conjuntamente, a aquel que reconoce al otro en toda su dimensión.

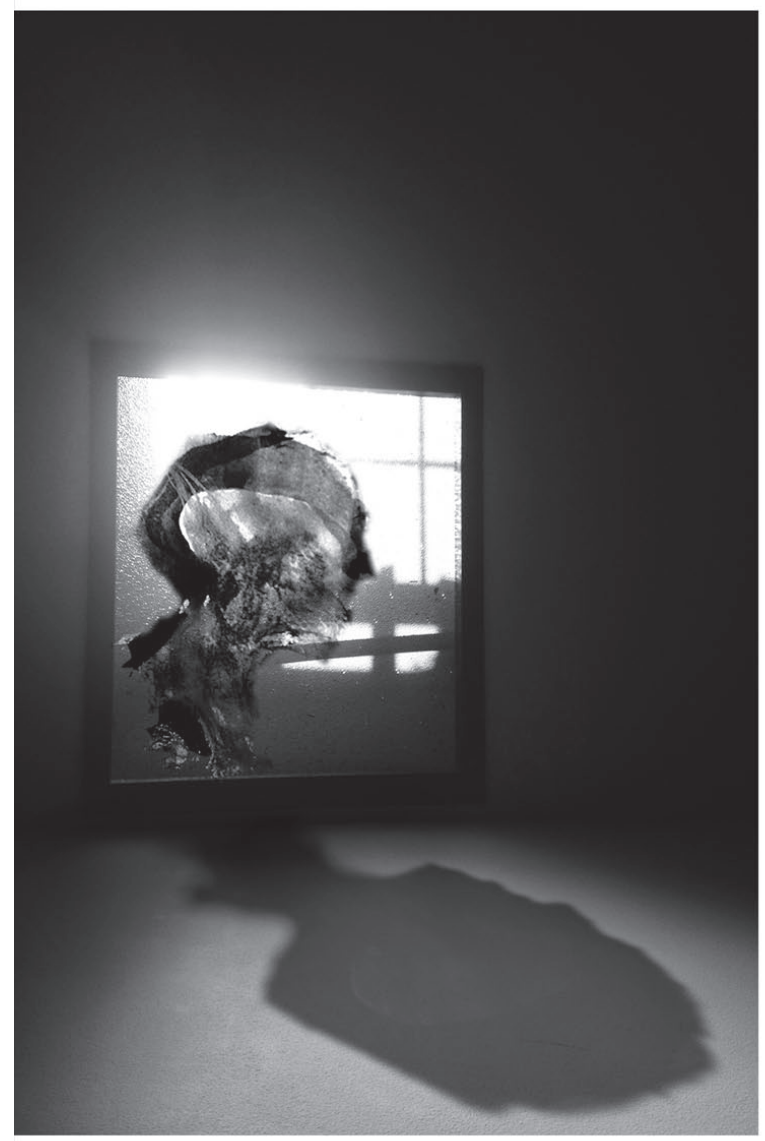

En esta perspectiva, es imperativo permitir que otras voces surjan. Otros testimonios que nos alejen de aquellos sobre los que la visión occidental de la ciencia se ha construido: moderna, blanca, masculina e ilustrada. La necesidad de potenciación (empowerment o empoderamiento) de mujeres, indígenas, gentes de color, víctimas y otros excluidos, está en estrecha relación con el reconocimiento de sus propias capacidades y con la posibilidad de que se creen oportunidades para desarrollarlas, en un intercambio de interpelación mutua, muchas veces desde su propio sufrimiento y silencio.

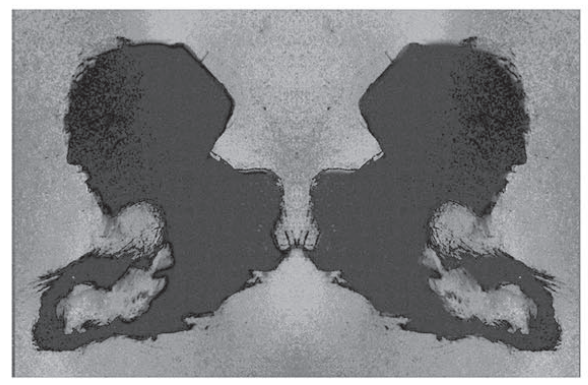


Los Estudios para la Paz asumen pues la tradición de nuevas maneras de entender el conocimiento y la ciencia, desde las Ciencias humanas y sociales. La Paz se convierte, desde esta mirada, en objeto de estudio, en categoría analítica.

"Necesitamos anclarnos en puntos seguros en un medio tormentoso y cambiante, desde el cual discutir la mejor manera de satisfacer las necesidades de la humanidad. Pero, además, aprendemos que estos anclajes no deben ser realizados una vez más por los poderosos, sino por las víctimas, los excluidos y los silenciados", asegura Martínez (2000, p. 81). En otras palabras, adoptar la perspectiva de la víctima. O como continúa él diciendo:

Necesitamos aprender de los ayudados. (Esto) supone el reto de establecer la relación conceptual y práctica entre vulnerabilidad y las capacidades de los que consideramos vulnerables. Es una variante del término de potenciación. Una de las paradojas de la acción urgente es que impone a los ayudados una forma de pensar, que puede constituir la razón misma de su indigencia, de su tener que menester. (...) Hemos de reconstruir conjuntamente las nociones de necesidad, sufrimiento y pobreza, a partir del reconocimiento de las capacidades de unos y otros (pp. 82-83).

"La vulnerabilidad puede desencadenar mecanismos de agresión, violencia y exclusión (...). Pero estamos trabajando la forma en que la vulnerabilidad también puede hacernos sentir la necesidad de las otras y los otros; que también puede originar ternura”, dice Martínez (2000, p. 92).

Retomaremos a manera de conclusión las palabras de Juan Manuel Jiménez, profesor de arqueología de la Universidad de Granada y otro importante artífice de la Investigación para la paz, de su artículo Pax homínida, cuando evoca al «viejo» de Dmanisi:

En 2005 se anunció en la revista "Nature" uno de las evidencias paleoantropológicas más interesantes de la última década, el hallazgo en Dmanisi (Georgia) de un cráneo con mandíbula asociada con una ausencia prácticamente total de la dentición. La antigüedad de este hallazgo, torna en torno a un millón ochocientos mil años. El individuo georgiano presentaba todos, menos uno, los alvéolos de los dientes superiores e inferiores cerrados y buena parte de los huesos maxilar y mandíbula reabsorbidos. ¿Qué significa esto? Que perdió los dientes mucho antes de que muriera. La cuestión clave está en cómo pudo sobrevivir sin poder masticar la comida. Pensemos por un momento que hace cerca de dos millones de años, el fuego ni se producía ni se controlaba, que muchos alimentos serían de origen vegetal (...) y que la carne cruda es blanda pero al ser muy elástica, 
hay que masticarla mucho. La interpretación por la que han optado los investigadores (...) es que este individuo debió contar con la solidaridad de su grupo para poder subsistir. Bien que le masticaran la comida, bien que le permitieran acceder de forma preferencial a las partes más blandas y alimenticias de las presas: médula, cerebro y vísceras. (...) De cualquier modo, parece que las conductas cooperativas estaban ya presentes en los albores del género Homo. (Jiménez, s.f., p.17)

Así pues, la presencia del otro es lo que nos hace existir. Pero la fragilidad es lo que nos hace visibles.

\section{Creonte, un gigante con pies de barro}

"Que se vea su cuerpo servir de pasto y de escarnio, de alimento para perros y aves de rapiña” (Sófocles, 2009, pp. 41-42). Creonte, el poderoso Rey de Tebas, ha decretado el destino del cadáver de su sobrino y prohíbe el entierro del cuerpo. No debe ser recubierto de tierra, no tendrá sepultura, ha confrontado su autoridad. Polinices fue desterrado de la ciudad por su hermano menor Eteocles pero regresó con la intención de desafiarlo y recuperar el trono que fuera de su padre Edipo. Pero es Creonte quien se presenta públicamente como legítimo heredero de la corona. Polinices y Eteocles se enfrentan en una guerra que termina con la vida de ambos y Creonte decide conceder los honores al héroe defensor de la ciudad y condenar a aquel que considera traidor. Tal es el castigo para aquellos que burlan el poder, para quien, como Polinices, "quiso quemar a fuego de raíz la tierra de sus padres y a los dioses de su linaje" (Sófocles, 2009, pp. 41-42). Creonte no puede flaquear ante sus súbditos, no puede permitir que el pueblo perciba cualquier limitación en el desempeño de su soberanía. "El que quebranta las leyes, o la fuerza, o pretende dar órdenes a quienes están en el poder, es imposible que obtenga mi aprobación. Al que pone en el mando la ciudad es menester obedecerle no solo en las minucias, sino en lo justo y aun en su contrario" (Sófocles, 2009, p. 69).

Así mismo, el castigo a Antígona debe ser ejemplar. En primer lugar porque es su familia. Es su sobrina, hija de su hermana Yocasta, pero otros lazos más intangibles unen a estos dos personajes. El Rey es quien obtiene la patria potestad de Ismena y Antígona pues Edipo le pidió que asumiera la custodia de sus hijas, "desgraciadas y dignas de compasión" (Sófocles, 2001, p. 39) y que las ayudara a no padecer el mismo sufrimiento suyo. Creonte carga pues con la responsabilidad de cuidar de ellas, de casarlas bien, de que tengan buena progenitura, ocupando así el lugar de padre que Edipo ha dejado vacío. La postura de Creonte es clara cuando le habla a su propio hijo: "Todo ha de postergarse anta la opinión de un padre” (Sófocles, 2009, p. 68). 
Por otra parte, Creonte debe castigar a Antígona por la condición femenina de su sobrina. “A mí, mientras esté con vida, no ha de mandarme una mujer" (Sófocles, 2009, p. 60). Por último, ensañarse con los muertos y con los supliciados es, quizás, la última forma de humillar a los derrotados y de hacerles sentir todo el poder del gobernante. Como dice Michel Foucault:

Hay que considerar la gran ceremonia del suplicio como una especie de ritual político. La coronación del Rey, era un tipo de ritual político, su entrada en la ciudad, era también un ritual político. Pues bien, los suplicios eran una especie de ritual político mucho más cotidianos que consistían en manifestar la fuerza física, material, del Rey en todo su esplendor y en toda su violencia y el cuerpo del supliciado debía mostrar en sus llagas, los gritos del supliciado debían manifestar en todos sus aullidos, la fuerza contundente del soberano. (Calderon, 2003)

Por otra parte, podemos mirar el comportamiento de Creonte a la luz de otro texto, esencial para la articulación de este artículo. En El proceso de la civilización (1989), Norbert Elías analiza el curso de las actitudes y los valores de la sociedad en Europa occidental desde el siglo VIII hasta el XIX. Desde la sociología, propone una nueva definición de los conceptos de identidad, así como un nuevo entendimiento de los hombres como participantes en un espacio donde se ponen en juego determinadas relaciones de libertad. El proceso civilizatorio tiene para Elías su origen en la interdependencia de los seres humanos. Aunque no ha sido racionalmente planificado, tampoco es el aleatorio resultado "del ir y venir de figuras desordenadas". Así, dice el sociólogo, "el cambio de comportamiento y de vida afectiva al que llamamos 'civilización' depende la interrelación intensa de los seres humanos y de su creciente interdependencia” (Elias, 1989, p. 298).

Para Elías, es en las sociedades donde el monopolio de la violencia es el más estable y se encuentra concentrado en el poder central, donde el individuo está en mayor soledad. Este tipo de sociedades, donde el poder de la violencia se encuentra monopolizado en la figura del Rey o del príncipe o, en su defecto, en las fuerzas militares que lo representan, son sociedades donde la red de relaciones interpersonales es más densa: la división del trabajo es fuerte, los impuestos elevados, las funciones y oficios diferenciados, y por ende, las acciones que vinculan a un individuo con los demás, múltiples y prolongadas. Esto genera una mayor dependencia funcional de unos a otros y los vuelve más dependientes y vulnerables. Al estar centralizado el poder de la violencia, el individuo está protegido frente al asalto repentino, frente a la intromisión brutal de la violencia física en su vida, sí. Pero, también está obligado a reprimir las propias pasiones, en una forma particular de coacción. Esto es lo que Elías llama "la contención regular de las manifestaciones instintivas y emocionales” (Elias, 1989, p. 460). Esta exigencia, inculcada por padres y maestros desde niños, moldea el comportamiento y la manifestación de los afectos del individuo en ámbitos pacificados pero a la vez, lo fragiliza. Los seres humanos se ven obligados a controlar sus emociones espontáneas, so pena de volverse débiles ante los ojos del monarca y de darle una mayor ventaja social a quienes quieran dominar sus afectos. La 


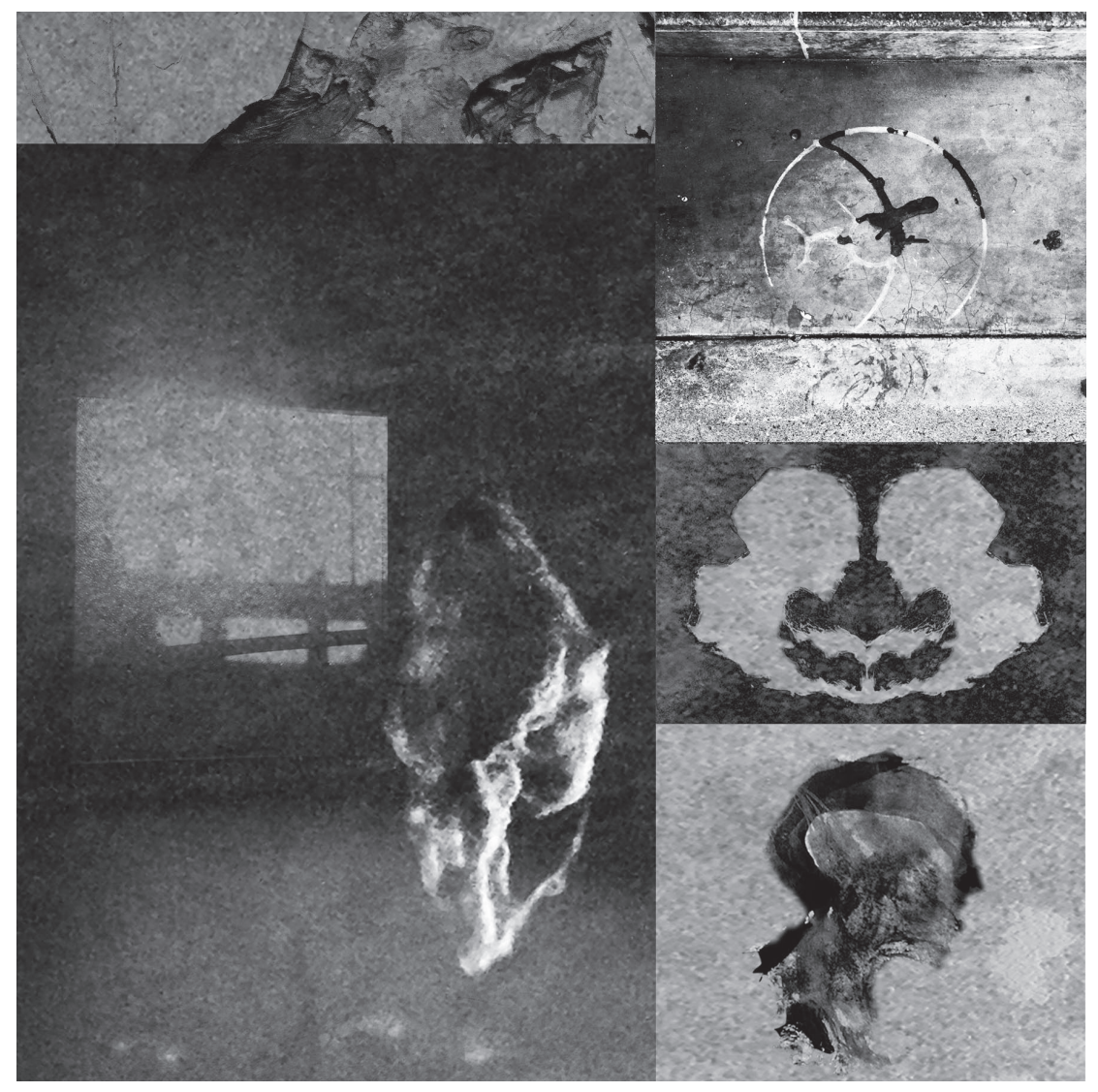

amenaza social es mayor para quien revela sus verdaderas emociones. La contención de las emociones puede ser tan fuerte que "el individuo no tiene posibilidad de manifestar sus afectos reprimidos, de satisfacer sus instintos sofocados" (Elias, 1989, p. 460). Esas heridas pueden, en el mejor de los casos, cicatrizar imperceptiblemente o, en el peor de ellos, resurgir al primer conflicto o momento de quiebre emocional.

Es una época en la que los entramados de dependencia que se entrecruzan en el individuo, se hacen más densos y más prolongados, una época en la que un número cada vez mayor de personas aparece más estrechamente unido y en la que aumenta la coacción del autocontrol. Al igual que la interdependencia, también se hace más intensa la observación recíproca de los hombres; la sensibilidad y consecuentemente, las prohibiciones, se hacen cada vez más diferenciadas y también más diferenciado, más amplio y más variable a tenor de un tipo superior de convivencia se hace aquello de lo que las personas se avergüenzan y que suscita el desagrado en los actos de los demás. (Elias, 1989, p. 503) 
Podríamos extrapolar las consideraciones de Elías en la caracterización que hace Jean Anouilh del personaje de Creonte. Después de enfrentar a Antígona, Creonte, el poderoso, el soberbio, se avergüenza de sus actos. Ha reconocido en la pequeña Antígona a un adversario.Y ella es implacable en su juicio:

- Creonte: Una mañana me desperté siendo rey de Tebas. Y Dios sabe que había otras cosas en la vida que me gustaban más que ser poderoso.

- Antígona: ¡Había que decir que no entonces!

- Podía hacerlo. Pero me sentí de golpe como un obrero que rechaza un trabajo. No me pareció honrado. Dije que sí.

- Bueno, lo siento por usted. ¡Yo no he dicho que sí! ¡Qué pueden importarme a mí su política, su autoridad, sus pobres historias! Yo puedo decir que no todavía a todo lo que no me gusta y soy único juez. Y usted con su corona, con sus guardias, con su pompa, sólo puede hacerme morir, porque dijo que sí.

- Escúchame.

- Si quiero, puedo no escucharlo. Usted dijo que sí. Usted no tiene nada más de qué enterarme. Yo sí. Está ahí bebiéndose mis palabras.Y si no llama a los guardias, es para escucharme hasta el final.

- ¡Me diviertes!

- No. Le doy miedo. Por eso trata de salvarme. A pesar de todo sería más cómodo conservar una pequeña Antígona viva y muda en este palacio. Es usted demasiado sensible para ser un buen tirano, eso es todo. Pero sin embargo me hará morir dentro de un instante, usted lo sabe, y por eso tiene miedo. Es feo un hombre que tiene miedo" (Anouilh, 2009, p. 173).

La legitimidad del soberano es radicalmente interpelada por aquellos que, según las leyes del Estado, son los que menor poder tienen, tal como la joven Antígona y el propio hijo de Creonte, Hemón, quien le dice, defendiendo a Antígona: "Es hermoso aprender de quienes hablan con prudencia” (Sófocles, 2009, p. 71). O más allá: "No hay ciudad que sea de un solo hombre”. En las duras palabras de su hijo, Creonte podría ser otro Edipo: un desterrado más pero de su propia tiranía: "Solo, podrías mandar bien en una ciudad desierta" (Sófocles, 2009, pp. 72-73).

En la pieza de Anouilh, Creonte cede. Como dice Luis Gil en la introducción de la obra de Sófocles (2009):

Creonte (...) se muestra totalmente incapacitado no ya para defender, sino para comprender esos derechos inherentes a la misma naturaleza del hombre y que, como tales, tienen por garantes a los dioses: el de Polinices, a ser enterrado; el de Antígona y Hemón, al amor. (...) Débil en el fondo, como indican su radical cambio de actitud y sus temores, desacostumbrado al ejercicio del poder, pretende con ejemplar y maquiavélico rigor dar ejemplo de energía en los 
comienzos de su mandato para asegurarse la obediencia temerosa de sus súbditos. Amparándose en la potestad de su cargo, aspira a revestirse de una autoridad (...) que finalmente no tiene. De ahí la carrera de desvaríos, tan maravillosamente descrita por el arte de Sófocles, que hacen de él lo que jamás hubiera querido ser: un tirano, un blasfemo, un theomachos. (pp. 17 y 19)

La obra representa una lucha de contrarios, de un hombre y una mujer, un tío y su sobrina, de la vejez contra la juventud, la autoridad y la despreocupación grave, lo divino y lo terrenal, los vivos y los muertos. Una figura insumisa frente a la intolerancia, la resiliencia política frente la tiranía, la alternativa de género frente al patriarcado. Veinticinco siglos después de que Sófocles le diera vida a Antígona, su obra sigue siendo un paradigma para la paz.

Antígona es una mujer alejada de la guerra pero víctima de ella, como todas aquellas que siguen reclamando el cuerpo de sus hijos, esposos o hermanos desaparecidos, en Colombia, México, Argentina, Chile, Uruguay, Guatemala, Perú y en tantas otras desoladas tierras; pidiendo la restitución de cuerpos sin enterrar, la restitución de la memoria, el deseo íntimo de que sus seres queridos vuelvan a existir, o vuelvan a ser visibles; de que las víctimas vuelvan a retomar el poder sobre su cuerpo. Como se pregunta Carlos Eduardo Sanabria, “ ¿Se trata acaso de una poética de la presencia y de la ausencia, de la mutua pertenencia de unos y otros cuerpos, en un incesante retraerse para traer a la presencia?" (Sanabria, 2012, p. 135).

Pero sobre todo Antígona en las versiones de Sófocles o de Jean Anouilh, ejemplifica el palíndromo "reconocer". Del griego palindromein ("volver a ir hacia atrás"), el palíndromo es una palabra que se lee igual hacia adelante que hacia atrás. A través de esta metáfora, la Antígona de Sófocles reconoce el poder de Creonte, aun siendo partícipe de su destino; el Creonte de Jean Anouilh admite legítimamente a Antígona como su adversario y se avergüenza de sus actos. Ambos han hecho un viaje hacia el otro, en clara interdependencia, reconociendo su plena existencia; ambos se han desestructurado para volver a construirse, aceptando las capacidades del otro. Ambos han sido herramientas para la paz (imperfecta).

\section{Flores para la tumba}

Finalmente, el miedo gana la joven Antígona. Tiene miedo de morir, miedo de que su hermano se quede sin sepultura, miedo también de seguir viva en caso de no lograr su cometido. Antígona está sola. Su lamento se dirige a Creonte:

¡Ay!, ¿Te ríes de mí? ¿Por qué, ¡por todos los dioses!, no reservas tu escarnio para cuando esté muerta, en vez de agraviarme mientras me ves aun? (...) A despecho de todo, os tengo de testigos de cómo y con qué leyes me encamino, sin ser llorada por mis seres queridos, hacia esa prisión a modo de tumba, tumba de un sepelio inaudito; ¡Ay, desdichada de mí!, que no comparto la morada ni con los hombres, ni con los cadáveres, ni con los vivos, ni con los muertos! (Sófocles, 2009, p. 81) 
Hacer Arte, es como si quisiéramos aplicar el concepto que propone Michel Foucault a partir del Panóptico de Bentham, pero al revés. Decía Michel Foucault:

La idea de que debamos absolutamente darles a aquellos que ejercen el poder un instrumento, dijéramos, óptico, para que aquellos sobre quienes se ejerce el poder y al mismo tiempo, los efectos de este poder, les sean visibles, eso es una preocupación fundamental. Dotar el poder de una mirada. Dar, por consiguiente, imponer a aquellos sobre quienes se ejerce el poder, darles una visibilidad integral, exhaustiva. (Calderon, 2003)

Estamos en la maquina panóptica, en ese modelo arquitectónico carcelario de vigilancia y control que permite a su guardián, refugiado en una torre central, observar a todos los prisioneros, recluidos en celdas individuales alrededor de la torre. Una estructura semicircular, con habitaciones que estén abiertas hacia el interior de un patio y cerradas hacia afuera. En el patio, en el medio, encontramos una torre, a partir de donde se mira hacia las habitaciones que dan al patio. El efecto más importante del panóptico es provocar en el detenido la ilusión de una vigilancia permanente, un estado consciente de percepción de visibilidad que garantiza el funcionamiento automático del poder, sin que ese poder se esté ejerciendo de manera efectiva en cada momento, puesto que el prisionero no puede saber cuándo se le vigila y cuándo no. Una mirada omnipresente, la mirada del otro, dominadora y vigilante, ilustración para Foucault de una sociedad disciplinaria y marcada por un poder riguroso que moldea las estructuras corporales y coerce la libertad.

Cuando hacemos danza, teatro, performance, podríamos pues decir que hacemos el camino inverso. Al empoderarse, los artistas demandan esa mirada del otro. Se exponen, piden mirarlos, te miran, te desafían. Expuesta su fragilidad, su vulnerabilidad se hace fortaleza.

La artista Marina Abramovic lo hace evidente en la preparación que hace con sus jóvenes pupilos:

El objetivo de esto es que tienen que actuar durante tres meses. Es una responsabilidad enorme. Deben crear su propio espacio carismático y para lograrlo, necesitan entrenamiento. La idea aquí es: vacíate, sé capaz de estar en el presente, pon tu mente aquí y ahora. Luego, algo emocional se abre, y eso es lo que queremos lograr. En las performances, debes tener un enfoque emocional. El diálogo entre el público y el artista es directo. Si estas presente en la obra en un $100 \%$, ese momento emocional les llega a todos. No hay manera de que no suceda. Todos sienten. El artista debe ser un guerrero. Tiene que tener determinación y resistencia para conquistar nuevos territorios y también, a sí mismo y a sus debilidades. (Ankers, 2012) 
Antígona ha dejado su condición de víctima, su dolor se hace legítimo, real y se logra nuevamente su humanización ya que lo vivido es inaceptable ética y socialmente para las víctimas. El dolor se hace propuesta y las víctimas actúan como ciudadanos y ciudadanas con una fuerza ética que moviliza para generar transformación social.

El "Cuerpo marcado por la guerra" vive dentro de nosotros, así que ¿por qué insistimos en esconderlo y suprimirlo? Parece que el cuerpo que nos envuelve sea perverso, sucio y cubierto de cicatrices. Pero, a pesar de todo, merece que lo mostremos y nos debería hacer sentir orgullosos. Es nuestra única arma para oponernos a la colonización por parte del poder del mercado y el dinero, y para evitar que se confisque nuestro derecho a expresarnos. (Mroué, 2010, p. 27)

Esta es la capacidad que tiene el Arte de conmovernos, de provocarnos, de generar sensaciones que nos hacen sentir vivos, con todo lo que significa estar vivo, lo hermoso, lo duro y lo bello de estar vivos. El Arte como forma de transmitir fragilidad, amor y ternura. El Arte como forma vital de empoderamiento pacifista. "La necesidad de empoderarse es la única posibilidad de transformación de una realidad desigual” decía Francisco Muñoz. La noviolencia se transforma así en una verdadera práctica para la libertad.

\section{Notas}

\footnotetext{
${ }^{1}$ Este ensayo hace parte de una investigación más amplia, en el marco del Doctorado de Paz y Resolución de Conflictos del Instituto de la Paz y los Conflictos de la Universidad de Granada. Los conceptos aquí empleados, en particular el de empoderamiento pacifista, son los propuestos por este Instituto y sus investigadores en el marco de la Investigación para la paz.
} 


\section{Referencias}

Anouilh, J. (1946). Antigone. Paris: Éditions de la Table Ronde.

(2009). Jezabel.Antígona. Traducido por: Aurora Bemárdez. Buenos Aires: Editorial Losada.

Elias, N. (1989). El proceso de la civilización. Investigaciones sociogenéticas y psicogenéticas. México: Fondo de cultura económica.

Jiménez, J. (s. f.). Pax homínida. Una aproximación imperfecta a la evolución humana. Granada: Universidad de Granada.

Jiménez, J. \& Muñoz, F. (eds). 2012. La paz, partera de la historia. Granada: Universidad de Granada.

Martínez, V. (2000). Saber hacer las paces. Epistemología de los estudios para la Paz. En Revista Convergencia, septiembre-diciembre, año 7, $\mathrm{N}^{\circ} 23$, Universidad Autónoma del Estado de México, pp. 49-96. Toluca, México.

Muñoz, F. (Junio 10 del 2014). El campo transdisciplinar para la Paz. Conferencia llevada a cabo en la Universidad del Valle, Cali.

Muñoz, F., Herrera J., Molina B. \& Sánchez S. (2005). Investigación para la paz y los Derechos Humanos en Andalucía. Granada: Universidad de Granada.

Muñoz, F. (ed) (2001). La paz imperfecta. Granada: Universidad de Granada, pp. 21-66.

Muñoz, F. y Molina, B. Una paz compleja, conflictiva e imperfecta. Ponencia del seminario Una paz compleja y conflictiva, sin fecha de publicación.

Mroué, R. (2010). El cuerpo marcado por la guerra. En Hacer historia. Reflexiones desde la práctica de la danza. De Naverán, Isabel (ed). Revista Cuerpo de letra, danza y pensamiento. $\mathrm{N}^{\circ} 3$. España: Centro Coreográfico Galego/ Institut del Teatre/ Mercat de les Flors.

Ospina, W. (Mayo 15 del 2014). La creación artística. Conferencia llevada a cabo en la Universidad del Valle. Cali.

Peláez, G. (2006). Los duelos en el cuerpo físico y social de las mujeres víctimas de la violencia. En Las viudas del conflicto armado en Colombia. Bogotá: ICANH.

Sanabria, C. (2012). Olvido y recuperación del cuerpo. Revista La Tadeo, No 77. Universidad Jorge Tadeo Lozano.

Sofocles (2001). Edipo Rey. Santiago de Chile: Pehuen Editores, (2009). Antígona. Traducción e introducción de Luis Gil. Barcelona: Random House Mondadori.

Steiner, G. (1996). Antígonas. La travesía de un mito universal por la historia de Occidente. Barcelona: Gedisa Editorial.

\section{Filmografía documental}

Ankers, M. (2012). Marina Abramovic, The artist is present. [documental]. Estados Unidos: Show Of Force / AVRO Television / Dakota Group.

Calderon, P. (2003). Foucault par lui-même. [documental]. Francia: BFC Productions / Arte France.

Lozano, J. \& Morris, H. (2011). Impunity. [documental]. Colombia.

Rincón, N. (2010). Los abrazos del río. [documental]. Bélgica y Colombia:VOA.

Revisado: noviembre 15 / Aprobado: noviembre 30 de 2014 